\title{
A POLÍTICA POR TRÁS DE UM NOME: CONSIDERAÇÕES SOBRE TERMINOLOGIA, DE ARQUEOLOGIA BÍBLICA ATÉ ARQUEOLOGIA DO ORIENTE PRÓXIMO
}

Gabriela Rodrigues ${ }^{1}$

\begin{abstract}
Resumo
Este artigo examina as tendências em terminologia para a prática arqueológica em Israel e na Palestina ao longo do tempo. A adoção de termos como "Arqueologia Bíblica" até a arqueologia de um período determinado numa região geográfica específica reflete não apenas o escopo da pesquisa, mas principalmente sua agenda política. Após uma apresentação dos termos mais comumente empregados na literatura, este texto discute como o nome da disciplina pode afetar a prática arqueológica no Oriente Próximo, ao mesmo tempo em que faz um apelo aos praticantes da disciplina que considerem a importância da discussão teórica.
\end{abstract}

\section{Palavras-chave}

"Arqueologia Bíblica"; "Arqueologia da Palestina"; Arqueologia do Oriente Próximo; Terminologia; História da Ciência; Arqueologia e Política.

\footnotetext{
${ }^{1}$ Doutora pela Universidade de Heildelberg, Heildelberg, Alemanhã. E-mail: gab.rodrigues@gmail.com
} 


\begin{abstract}
This paper examines the trends in terminology for the archaeological practice in Israel and Palestine through time. The adoption of terms from 'Biblical Archaeology' to the archaeology of a specific age in a determined geographical area appears to reflect not only the research scope but also its political agenda. After an overview of the most common terminology in the literature, the paper addresses how these names can affect the practice of archaeology in the region of the Near East, in an appeal for its practitioners to the theoretical aspects of the discipline.
\end{abstract}

Keywords

'Biblical Archaeology'; 'Archaeology of Palestine'; Near Eastern Archaeology; Terminology; History of Science; Politics of Archaeology. 


\section{Introdução}

Ao longo de sua história, a arqueologia praticada na região conhecida por alguns como a Terra Santa recebeu diferentes nomes e definições. Essa diversidade de classificação é, de fato, resultado da própria história de uma disciplina, a qual é tão controversa quanto a região em que é praticada. Na região de Israel e da Palestina - bem como em todo Oriente Próximo - política e religião foram desde sempre dois elementos indissociáveis. A pesquisa científica desenvolvida na região nos séculos XIX e XX em grande parte por europeus configura-se como um elemento adicional nessa trama, tornando praticamente impossível a separação entre ciência, fé e política. Nesse contexto, as pesquisas arqueológicas na região oscilaram desde o início entre o campo dos estudos bíblicos e a disciplina arqueológica; daí a grande dificuldade em definir a disciplina seu escopo e objetivos - e sua terminologia.

O termo popular "Arqueologia Bíblica" evidencia uma conexão explícita entre arqueologia e Bíblia. Apesar de sua ampla adoção, seu significado está longe de ser absoluto. Há, por um lado, a arqueologia bíblica como a arqueologia de sítios mencionados no texto bíblico, como, por exemplo, a arqueologia de Jerusalém, Jericó ou Meguido. Por outro lado, há a arqueologia do Oriente Próximo que foca em períodos históricos nos quais a narrativa bíblica teria emergido ou a que ela se refere. Além disso, há também a arqueologia motivada por um tema bíblico específico, como a conquista de Canãa ou a Monarquia Unificada.

De maneira alternativa, os termos "Arqueologia da Terra Santa" (Negev, 2001; Magness, 2012) ou "Arqueologia na Terra Santa" (Kenyon, 1960; Balter, 2000) também foram usados. "Arqueologia da Palestina" também é uma escolha tradicional entre praticantes de arqueologia na região. A "Arqueologia do Antigo Israel", por outro lado, é vista como uma pequena parte da Arqueologia Palestina (Franken e Franken-Battershill, 1963).

Por fim, há também "Arqueologia do Oriente Próximo". "Oriente Próximo", assim como os termos "Oriente Médio" e "Extremo Oriente" também é uma criação ocidental popularizada nos séculos XIX e XX, na tentativa de especificar regiões dentro do conceito amplo de Oriente. Oriente Próximo é o nome normalmente adotado para descrever a porção moderna de terra entre o Mar Mediterraneo ao Iraque, do Egito a Turquia. O termo correto para se referir À mesma região geográfica em tempos antigos é "Antigo Oriente Próximo". 
Atualmente não há um consenso geral em relação a qual termo deva ser adotado. $\mathrm{O}$ estudo dos diferentes nomes conferidos à disciplina ao longo do tempo fornece informações importantes sobre a identidade de uma disciplina, forjada em meio a conflitos e disputas. O objetivo deste texto é primeiramente de apresentar a terminologia e seus usos e, na sequência, discutir os efeitos desses usos na interpretação e na prática da arqueologia na região de Israel e da Palestina. Finalmente, o texto pretende chamar a atenção dos pesquisadores engajados nessa área, do poder e da limitação de seu trabalho, dentro da Arqueologia.

\section{Arqueologia Bíblica}

Para o teólogo estadounidense que ficou conhecido como o "pai da Arqueologia Bíblica", o termo deve abarcar a arqueologia "de todas as terras bíblicas, da India à Espanha e do sul da Rússia até a Arábia do Sul, incluindo toda a história desse território desde cerca de 10 mil a.C- ou até um pouco antes - até o tempo presente“ (Albright, 1966: 13). De acordo com Cross (1973: 3), a Arqueologia Bíblica de Albright deveria incluir "papiros do Egito, o onomasticon dos Amoritas, um selo cilíndrico da Grécia, marfins fenícios da Espanha, um óstracon de Edom, um vaso ateniense pintado, um crânio de Carmel“ .

William F. Albright (1891-1971) foi um estudioso da Bíblia ativo na Palestina entre as décadas de 1920 e 1960. Ele foi o primeiro a registrar uma definição tão ampla do termo Arqueologia Bíblica. Essa interpretação bastante geral e inclusiva do termo ressalta a principal característica da pesquisa arqueológica bíblica, desde seus primeiros passos até o tempo de Albright: o ponto de partida da investigação era a Bíblia.

Desde os primeiros esforços científicos na Palestina, a arqueologia bíblica foi frequentemente interpretada como o estudo da antiguidade da Bíblia e, por conseguinte, encontrava no texto bíblico, a sua principal fonte de pesquisa. De acordo com essa perspectiva, a Bíblia seria capaz de oferecer informações específicas sobre o cotidiano à época, em seus aspectos políticos, religiosos e domésticos, que poderiam ser facilmente combinadas com as escavações arqueológicas, cujo resultado seria capaz de ilustrar tais aspectos do passado (Davis, 2004: 20).

O papel central que o texto bíblico ocupava nessas pesquisas é evidenciado pelos sujeitos envolvidos nelas, ao longo de suas primeiras décadas. As primeiras expedições antes da Primeira Guerra Mundial e 
durante o Mandato Britânico foram comumente organizadas e conduzidas por especialistas em Bíblia. Além de Robinson e Albright, elas incluíram pesquisadores europeus como E. Sellin e R. de Vaux.

Por outro lado, como ressalta Dever (2003 : 57), Albright fez também uso frequente do termo "Arqueologia Palestina". De fato, o pesquisador responsável pela divulgação do termo Arqueologia Bíblica é George E. Wright, famoso pupilo de Albright. Em sua definição, Arqueologia Bíblica seria uma "variedade especial 'de gabinete' da arqueologia geral", a qual estaria, por um lado "preocupada de forma perspicaz com a estratigrafia e a tipologia quem embasam os métodos da arqueologia moderna", mas que teria a "compreensão e a exposição das Escrituras com papel o objetivo central" (Wright, 1947a: 7, 1947b: 74). Wright também nomeou a revista que ele criou para a American School of Oriental Research (ASOR) de "O Arqueólogo Bíblico". Ela foi publicada sob esse título entre os anos de 1938 até 1998, quando a ASOR alterou o nome para "Arqueologia do Oriente Próximo".

O uso de "Arqueologia Bíblica" nunca foi uma exclusividade norteamericana. De fato, o termo foi adotado em muitas línguas e pode ser encontrados em publicações até hoje. Na França, por exemplo, podemos citar a publicação Cadernos de Arqueologia Bíblica, sob Andre Parrot. Entre pesquisadores de língua alemã, Arqueologia Bíblica foi usado em livros, cursos e dicionários desde o fim do século XVIII. Entre 1787 e 1799, Johann Joachim Bellermann (1754-1842), professor em Berlin, publicou o seu Manual de Literatura Biblica, cujo primeiro volume foi dedicado à Arqueologia Bíblica, Dey ano mais tarde, Johann Jahn (1750-1816) publicou o primeiro livro de uma série intitulada Arqueologia Bíblica. Os volumes eram dedicados às Antiguidades Domésticas (1817), Antiguidades Políticas (1825) e às Antiguidades Sacras (1805). Ademais, entre 1810 e 1842, Wilhelm Gesenius (1786-1842), lecionou na Universidade de Halle cursos sobre Arqueologia e Antiguidades Bíblicas, bem como sobre Arqueologia Hebraica (Hübner 2013). Atualmente, o manual mais usado no país sobre o tópico leva o título de Introdução à Arqueologia Bíblica, por Volkmar Fritz.

Arqueologia Bíblica ainda é um termo bastante utilizado e aparece hoje não só em capas de livros e revistas (Cline, 2009; ver também Biblical Archaeology Review), mas também aparece mais de 3,5 milhões de vezes no Google. Está também em enciclopédias de arqueologia como a Encyclopedia of historical archaeology (Orser, 2002) and Encyclopedia of Archaeology (Pearsall, 2008). No último caso, no entanto, com uma definição que inclui um escopo geográfico e cronológico mais amplo, como a pesquisa do "Crescente Fértil", do período Neolítico até a Antiguidade Tardia (Sharon, 2008: 920). 


\section{Archaeology of Palestine}

Durante o século XIX, no entanto, a maioria das publicações como diários de viagem e relatórios de exploração adotavam o termo Palestina para descrever a região, em detrimento de qualquer outro nome relacionado ao texto bíblico. Entre eles estão o alemão Ulrich Jasper Seetzen (17671811) e o britânico James Silk Buckingham (1786-1855)2 ${ }^{2}$ Até mesmo o estudioso bíblico Edward Robinson usou Palestina no título de seu renomado livro, Pesquisas Bíblicas na Palestina, no Monte Sinai e na Arábia Pétrea (1841).Palestina também foi a descrição adotada por Frederic Bliss and Stewart Macalister para seu relatório Escavações na Palestina entre os anos de 1898-1900 (1902).

É possível dizer que a escolha do termo Palestina entre esses pesquisadores não foi deliberada; ou seja, eles estavam apenas seguindo o status quo. $\mathrm{O}$ uso do termo baseava-se numa tradição que remonta a escritores gregos antigos, como Heródoto, quem costumava identificar a área entre o Mar Mediterrâneo e o Rio Jordão como Palestina (Rainey, 2001).

Entretanto, quando Albright chegou à região, Palestina já tinha um outro significado. Tratava-se de uma outra Palestina, criada após a Primeira Guerra Mundial, quando a Questão Palestina, a Declaração de Balfour e a ideia do estabelecimento de um território nacional para os Judeus na Palestina fez com que uma (re)definição do termo Palestina e de suas bordas fosse necessária (Susser, 2012).

Apesar disso, o termo ainda segue em uso. Por um lado, por pesquisadores que conduzem escavações em Israel, mas principalmente na Jordânia, em busca de uma descrição mais genérica para sua profissão (Rast, 1992: 16). Além disso, Arqueologia Palestina é hoje comumente usada para se referir às pesquisas dentro do atual território palestino sob a direção do Departamento de Antiguidades e Patrimônio da Autoridade Palestina e da Universidade Al-Quds (Bohannon, 2006).

\footnotetext{
2 Seetzen (1854) Reisen durch Syrien, Palästina, Phönicien, die Transjordan-Länder, Arabia Petraea und Unter-Aegypten; Buckingham (1821) Travels in Palestine Through the Countries of Bashan and Gilead, East of the River Jordan.
} 


\section{Terminologias Alternativas}

Conhecido por liderar as discussões epistemológicas no campo da Arqueologia Bíblica, Dever propôs, no início da década de 1970, a adoção de um novo nome: "Arqueologia Sírio-Palestina". Ao menos no campo teórico, o acadêmico mostrava-se incomodado com a relação umbilical entre Bíblia e arqueologia na Palestina (Dever, 1982: 103). Insipirado pelo desenvolvimento da chamada Nova Arqueologia nos Estados Unidos, Dever passou a defender mudanças necessárias na arqueologia bíblica, em prol de discussões antropológicas e processuais e do abandono da orientação teológica. Nesse contexto, o autor fala de morte, declínio e queda da Arqueologia Bíblica.

De acordo com sua definição, Arqueologia Sírio-Palestina tornou-se uma "disciplina arqueológica autônoma, não mais um campo auxiliar dos estudos bíblicos e teológicos" no momento em que seu escopo geográfico passou das Terras da Bíblia para a região "sul e central da Síria e da Palestina, leste e oeste do Jordão (i.e. moderno Israel, Jordânia, Líbano e outras partes da Síria(, ou melhor, a antiga 'Grande Canaã'”'. Além disso, seu escopo cronológico expandiu-se "muito além do 'período bíblico', abrangendo tudo desde o Paleolítico Inferior até o período Otomano". Ele ainda classifica os objetivos e métodos da disciplina como os "de qualquer outro ramo da arqueologia (e antropologia)". De fato, ele descreve de forma explícita sua agenda como "não derivada da Bíblia, muito menos de questões teológicas" (Dever, 2001: 60-61).

O pesquisador estadounidense argumenta que tais esforços em reviver e popularizar o termo "Sírio-Palestina" - o qual já era usado por Albright foram amplamente aceitos, especialmente durante as décadas de 1980 e 1990, até mesmo por pesquisadores israelenses (Dever, 2001: 62; Cf. Mazar 1990).

De acordo com Burke (2006: 83), no entanto, "Arqueologia do Levante" tem sido adotado com maior frequência, em especial por pesquisadores europeus. Ele defende seu uso baseado não apenas em questões geográficas, mas também na observação da cultura material da região, o que torna "Arqueologia do Levante" o primeiro nome forjado a partir de uma lógica interna à prática arqueológica da região. O termo pressupõe, no entanto, que Levante seja uma "zona cultural contígua" (Burke, 2006: 100).

Além disso, arqueólogos também empregam os termos "Arqueologia de Israel" ou "da Jordânia, ou preferem adotar o período histórico da pesquisa em seu nome, como arqueologia da Idade do Ferro. 


\section{Por que a terminologia importa?}

Em termos teóricos, a forma como um pesquisador se refere ao seu campo de estudos, assim como a maneira de retratá-lo e reportar suas atividades diz muito sobre esse pesquisador e o caráter de sua pesquisa, seu ponto de partida e objetivos.

Arqueologia como a conhecemos hoje é um fenônemo moderno. Isso não quer dizer apenas que a Modernidade conferiu à arqueologia condições para sua emergência (Thomas, 2004), mas também que conceitos e operações modernos, assim como ilustração, industrialização, capitalismo, imperialismo, colonialismo, ou distinções como antigo e moderno, civilização e barbárie são partes constituintes da arqueologia (González-Ruibal, 2013b).

O desenvolvimento de uma consciência arqueológica, ou seja, um consenso em relação à sua identidade, modelos e teorias (Hodder, 2003), levou a disciplina à sua independência, ao reconhecimento de sua epistemologia (Renfrew e Bahn, 2005) e provocou a ruptura nos limites de sua inocência (Clarke, 1973: 6).

Consequentemente, arqueólogos passaram a refletir sobre a história de sua própria disciplina. Essa busca pelas origens e evolução da arqueologia - ou ainda sua genealogia - tem revelado seu lado mais sombrio (Silberman, 1989; Kohl e Fawcett, 1995; Marchand, 1996; Meskell, 1998; Hingley, 2000; Díaz-Andreu, 2007; Ben-Yehuda et al., 2007; Funari e Ferreira, 2008; Hamilakis, 2009). O estudo da história e dos desenvolvimentos teóricos da prática arqueológica tornou-se então uma ferramenta importante a favor de uma disciplina mais igualitária e libertária, capaz de promover interpretações mais complexas do passado (Gnecco, 2009; Haber, 2012).

Não obstante, a prática arqueológica no Oriente Próximo tem sido repetidamente retratada como uma sequência de feitos de pioneiros, os pais fundadores e suas grandes descobertas, traçando uma origem nobre - i.e. europeia e iluminada - para a arqueologia da região. Como Meskell (1998: 2) notou há alguns anos as arqueologias do Mediterrâneo, Oriente Próximo, e do Egito seriam campos marginalizados dentro da disciplina e seus praticantes ainda estariam presos às amarras da arqueologia histórico-cultura e, por isso, reticentes em se envolver com questões mais contemporâneas como política ou a prática da disciplina.

O ponto deste texto não é discutir se essa crítica ainda cabe, vinte anos depois. Ele é, na verdade, um lembrete de que o ato de nomear e contar a 
história de uma disciplina configura uma oportunidade de reforçar suas próprias reivindicações como praticante dessa disciplina (Haber e Roberts, 2004). Dito isso, cabe ressaltar que apesar da terminologia não ser uma questão importante para pesquisadores engajados na arqueologia do Oriente Próximo atualmente, ela é uma fonte importante de reflexão, capaz de identificar agendas, filiações, objetivos, ou seja, a própria identidade da disciplina ao longo do tempo.

Com sua definição de Arqueologia Bíblica, Albright explicitou claramente sua posição política e também teórica, ou seja, desmentir os críticos bíblicos pelo estudo da evolução da história das religiões - "da Idade da Pedra ao Cristianismo" até seus desenvolvimentos posteriores no mundo Greco-Romano (Albright, 1933, 1940, 2006, 1966). De acordo com o pesquisador, para investigar tal evolução arqueologia e estudos históricos (inclusive língua e literatura) teriam de ser combinados. Ele partia do texto bíblico como a principal fonte para sua pesquisa científica e olhava através dele para o material arqueológico da Terra Santa a fim de elucidar a interpretação de passagens bíblicas específicas. Com Albright, a Arqueologia Bíblica consolidou-se como um "processo de construir teoria bíblica a partir da materialidade da arqueologia" (Davis, 2004: 85).

Assim, dentro do que ficou conhecido como "escola albrightiana", arqueologia era usada como uma ferramenta para provar a veracidade da Bíblia. Sua importância limitava-se à sua capacidade de oferecer evidências materiais para uma interpretação que já existia. A Arqueologia Bíblica não se configurava, então, como uma disciplina autônoma, mas sim como auxiliar da Teologia.

O período do Antigo Testamento era o foco principal da Arqueologia Bíblica. Isso porque a maioria das grandes controvérsias teológicas da época relacionavam-se a ele, desde a Babel-Bibel Streit no início do século $\mathrm{XX}$, até os esforços de Albright e Wright em combater o que aquele classificou como "nihilismo" alemão de Albrecht Alt, Martin Noth e Gerhard von Rad (Soggin, 1960; Wright, 1960; Rad, 1961).

Posteriormente, o termo "Arqueologia Bíblica" ganhou um caráter patriótico, especialmente depois de Dever chamá-la de um fenômeno norte-americano. Ele relaciona a existência da Arqueologia Bíblica com a decisão americana de buscar "provas 'externas', fornecidas pelas descobertas arqueológicas" (Dever ,1997: 315), até quando a Nova Arqueologia revolucionou a arqueologia dos Estados Unidos e transformou Arqueologia Bíblica num termo inaceitável. é claro que isso só pode ser interpretado como uma insistente reivindicação de exclusividade ou liderança americana no campo da Arqueologia Bíblica, a 
ponto de ignorar os desenvolvimentos da disciplina antes da Primeira Guerra Mundial.

Em língua alemã, "Arqueologia Bíblica" era entendida como o estudo daquilo mencionado na Bíblia - no sentido de conceitos e ideias. Por isso, o termo era usado como sinônimo de "Antiguidades Bíblicas" e seu estudo, bem como de "Arqueologia Hebraica" 3 . À época das primeiras publicações, "arqueologia" era um sinônimo comum para "antiguidades". Assim, autores combinaram tópicos relacionados desde à administração, governabilidade e guerras, até detalhes da vida cotidiana, nascimento, casamento e morte, bem como dieta, culto e práticas religiosas. A maioria dos textos começava com uma introdução geral à geografia, clima, fauna e flora das Terras Bíblicas, seguida por uma história de Israel de Abraão até os romanos (Hübner, 2013: 461). Os textos também costumavam trazer uma apresentação dos vizinhos de Israel, já que para ser Arqueologia Bíblica, como registrou Jahn (1817: 3), o pesquisador tinha de conhecer os egípcios, os hititas, os assírios, os babilônios, os persas e os árabes.

Dessa forma, o uso de Arqueologia Bíblica entre pesquisadores de língua alemã atualmente é bastante controverso (Rodrigues, 2017). Para adicionar à controvérsia, quando o termo passou a fazer referência a escavações arqueológicas e à coleta de material do solo, ele foi entendido como uma Altertumswissenschaft (Baentsch, 1909), ou seja, o estudo de coisas reais e paupáveis (realia) na forma de artefatos e estruturas relacionadas à Bíblia. Assim como a Altertumswissenschaft clássica partia de documentos escritos para interpretar os vestígios materiais dos antigos gregos e romanos, a Arqueologia Bíblica usava o texto bíblico para conduzir escavações e interpretar seus resultados. Consequentemente, $\mathrm{o}$ termo Arqueologia Bíblica em língua alemã permaneceu intrinsicamente relacionado aos estudos bíblicos.

Quando Dever passa a advogar contra o uso de "Arqueologia Bíblica" apesar de não propor a laicização da prática arqueológica na Palestina ${ }^{4}$ -

\footnotetext{
${ }^{3}$ Kalthoff, Handbuch der hebräischen Alterthümer (1840); Volz, Die biblischen Altertümer (1914); Rosenmüller, Handbuch der biblischen Alterthumskunde (1823); Allioli, Handbuch der biblischen Alterthumskunde 1 u. 2 (1844); Faber, Archäologie der Hebräer (1773); Wette, Lehrbuch der Hebräisch-Judischen Archäologie (1814); Benzinger, Hebräische Archäologie (1894).

4 Apesar de Dever ser conhecido por sua campanha contra a tradicional orientação bíblica da prática arqueológica em Israel e pela importância de seguir as discussões de arqueologia pelo Mundo, (ver Silberman, 1998: 177), ele ainda parece acreditar no poder da Arqueologia para iluminar a Bíblia, ou até de comprová-la (Dever, 1982, 1995, 2001; Cf. Finkelstein, 2007.)
} 
ele faz uma grande contribuição em direção à independência da disciplina. Ao olhar para a Nova Arqueologia, o pesquisador enfatiza a importância de seguir metodologias e discussões teóricas próprias. $\mathrm{O}$ pensamento processual na Nova Arqueologia confere à cultura material o status de evidência per se, capaz de oferecer informação sobre a sociedade na qual foi criada e utilizada, independente de qualquer fonte escrita (Binford e Binford, 1968). Daí o problema de uma arqueologia orientada pela Bíblia, como a praticada sob o termo Arqueologia Bíblica.

Essa corrente da teoria arqueológica surgiu nos Estados Unidos, mas não demorou muito para que se fiyesse presente nas discussões globais da arqueologia. Nos anos 1980, a arqueologia se abre ao Pós-modernismo, na forma de Arqueologia Pós-processual, que é considerada a escola de pensamento mais desconstrucionista dentro da arqueologia.

De fato, alguns casos em que a evidência arqueológica foi tradicionalmente interpretada como prova da narrativa bíblia acabaram perdendo a credibilidade material, com o desenrolar das pesquisas científicas. Por exemplo, a narrativa dos Patriarcas no livro de Gênesis (12-50), a conquista de Canaã pelos israelitas segundo Josué (6-12), algumas descrições de práticas religiosas do Deuteronômio (Dever e Clarke, 1977; Finkelstein, 1988; Biran, 1994; Finkelstein e Silberman, 2002; Dever, 2003b; Bartlett, 2009).

Por outro lado, ainda existe um grande apelo à Arqueologia Bíblica tradicional, motivada e, até proporcionada por interesses religiosos. Grande exemplo disso é a busca incessante por evidências do reino glorioso de Davi e Salomão como descrito nos livros de Samuel e Reis.

Apesar de toda uma narrativa de conquistas e construções, não há evidências arqueológicas que suporte a descrição da Monarquia Unificada. Mais recentemente, após um século e meio de trabalho de campo em Jerusalém, as escavações de Eilat Mazar na Cidade de Davi e no Ophel produziram fragmentos de evidências (de acordo com a arqueóloga) da exatidão histórica da Bíblia. Dentre eles há artefatos que ela interpreta como pertencentes ao palácio do rei bíblico Davi (Mazar 2006; 2009). As escavações de Zosef Garfinkel e Saar Ganor no sítio de Khirbet Qeiyafa, entre os anos de 2007 e 2013, configuram outro grande exemplo. Esse projeto é conhecido pela publicidade atingida após a divulgação de que estariam escavando uma fortaleza judaica do período do rei bíblico Davi (Garfinkel, Ganor, 2009; Garfinkel, Ganor, Hasel, 2014). 
Em ambos os casos, os achados devem atestar a importância de Jerusalém e de seu organizado sistema administrativo durante o século $X$ AEC, como descrito no texto bíblico. Os resultados dessas escavações foram vehementemente questionados; eles foram considerados exemplos perfeitos da argumentação circular que usa a Bíblia como evidência principal de sua própria precisão (Finkelstein et al., 2007; Finkelstein, 2011; Faust, 2012; Na'aman, 2008a, 2008b; Dagan, 2009; Finkelstein, Piasetzky, 2010; Finkelstein, Fantalkin, 2012).

De forma alternativa, para responder à tal tendência, há casos em que a relação entre arqueologia e o texto bíblico é propositadamente evitada. Por exemplo, no debate sobre a cronologia dos estratos da Idade do Ferro no Levante, Israel Finkelstein (1996; Finkelstein, Piasetzky, 2011) sugeriu que as datas do período do Ferro IIa - tradicionalmente baseadas na narrativa bíblica a Monarquia Unificada - passassem do século X AEC para a primeira metade do século $X$ até o fim do IX ou mesmo começo do século VIII AEC.

Finkelstein chama sua pesquisa de "Arqueologia da Idade do Ferro", ou seja, sem uma conexão a priori com nenhuma periodização bíblica. Para ele, ao deixar de lado o pano de fundo bíblico e tentar entender sítios como Meguido - e outros tantos já interpretados de acordo com a argumentação circular mencionada acima - por meio do registro arqueológico, fica claro que a datação tradicional não confere com a estratigrafia. Foi daí que ele partiu, usando primeiramente a datação relativa, para depois sugerir a datação absoluta, com o desenvolvimento de técnicas como o Carbono 14 (Finkelstein, Piasetzky, 2010). Seu ponto de partida era o material arqueológico, interpretado de acorso com parâmetros arqueológicos.

A "Arqueologia da Idade do Ferro" de Finkelstein é um exemplo de uma prática arqueológica per se num sítio arqueológico importante para a história bíblica. Historiadores são convidados a adotar informações provindas da arqueologia em seus esforços para melhor entender a história do Antigo Israel, bem como de todos os sítios arqueológicos relacionados à narrativa bíblica. Como essas histórias serão contadas, no entando, depende do interesse e do compromisso do pesquisador. 


\section{Considerações Finais}

A Arqueologia vem sendo praticada no Oriente Próximo desde o século XIX, passando pelas Guerras e Mandatos por viajantes amadores, engenheiros de exércitos, padres e pastores - e, às vezes, também por arqueólogos formados; depois disso, o trabalho foi conduzido por escolas nacionais de arqueologia e, novamente, por instituições internacionais, até os dias de hoje. Não há dúvidas de que a disciplina foi moldada pelos eventos políticos da região, tendendo ora para a orientação religiosa, ora para a nacionalista.

De fato, não há necessidade de uma abordagem consensual ou uma terminologia unificada para a prática arqueológica no Oriente Próximo. No entanto, a falta de interesse dos atuais praticantes por essa longa história da disciplina, coloca-os na perigosa posição de repetir e reproduzir os mesmos e velhos discursos, ignorantes do poder e das implicações da disciplina.

Assim, "Arqueologia Bíblica" deve ser vista como um fenômeno histórico ligado a uma mentalidade específica imbricada em discussões teológicas e interesses políticos do período em que ela se desenvolveu (Silberman, 1982). Além disso, resultados de pesquisas anteriores devem ser reexaminados à luz do contexto epistemológico em que eles foram produzidos. Finalmente, trabalhos futuros devem se comprometer em evidenciar seus pontos de partidas e agendas, não apenas em prol de uma prática arqueológica mais transparente, mas principalmente de uma engajada em não mais reproduzir conceitos tradicionais, datados e muitas vezes opressivos.

\section{Agradecimentos}

Há alguns anos, o Professor Pedro Paulo Funari me ensinou a ser crítica, a não subestimar nada, a sempre considerar intenções e agendas, mesmo que não explícitas. Ele provavelmente tinha a intenção de fazer de mim uma boa aluna, pesquisadora, alguém capaz de interpretar um texto acadêmico para além de suas linhas. O resultado disso, no entanto, foi muito mais impactante: ele transformou o meu jeito de pensar e ver o mundo não apenas como acadêmica, mas como pessoa. Por isso - e por inúmeros outros ensinamentos - eu sou extremamente grata pela oportunidade de ter sido pupila desse grande pesquisador e grande incentivador da busca ilimitada de conhecimento. A História Antiga e a 
Arqueologia enriqueceram muito com sua dedicação e carinho. Obrigada, professor!

\section{Referências Bibliográficas}

ALBRIGHT, William. F. The Archaeology of Palestine and the Bible. Fleming H. Revell Company, 1933.

ALBRIGHT, William. F. From the Stone Age to Christianity: Monotheism and the Historical Process. Baltimore: The John Hopkins Press, 1940.

ALBRIGHT, William. F. Archaeology, historical analogy \& early Biblical tradition Louisiana State University Press, 1966.

ALBRIGHT, William. F. Archaeology and the religion of Israel. 5th edition. London: Westminster John Knox Press, 2006 [1946].

BALTER, Michael. Archaeology in the Holy Land. Science. Vol. 287, Nr. 5450, 2000, p. 28-29.

BARTLETT, John R. Archaeology: In. LIEU, J. M. and ROGERSON, J.W. (eds.) The Oxford Handbook of Biblical Studies. Oxford: OUP, 2009, p. 54-73.

BEN-YEHUDA, Nachman; KOHL, Philip; KOZELSKY, Mara. Selective Remembrances: Archaeology in the Construction, Commemoration and Consecration of National Pasts. Chicago: University of Chicago Press, 2007.

BINFORD, Sally. R.; BINFORD, Lewis. R. New Perspectives in Archaeology. Chicago: Aldine Publishing Company, 1968.

BIRAN, Avraham. Tel Dan: Biblical Texts and Archaeological Data. In: COOGAN, et. al. (eds.) Scripture and Other Artifacts. Louisville: John Knox Press, 1994, p. 1-17.

BOHANNON, John. Palestinian Archaeology Braces for a Storm. Science. Vol. 312, Nr. 5772, 2006, p. 352-353.

BURKE, Aaron A. The Archaeology of the Levant in North America: The Transformation of Biblical and Syro-Palestinian Archaeology. LEVY, Thomas E. Historical Biblical Archaeology and the Future: The New Pragmatism. New York: Routledge, 2014, p. 81-95. 
CLARKE, David L. Archaeology: The Loss of Innocence. Antiquity. Vol. 47, Nr. 185, 1973, p. 6-18.

CLINE, Eric, H. Biblical Archaeology: A Very Short Introduction. Oxford: OUP, 2009.

CROSS, Frank M. W. F. Albright's View of Biblical Archaeology and Its Methodology. BA. Vol. 36, Nr. 1, 1973, p. 2-5.

DAGAN, Y. Khirbet Qeiyafa in the Judean Shephelah: Some Considerations. Tel Aviv. Vol. 36, 2009, p. 68-81.

DAVIS, Thomas W. Shifting Sands: The Rise and Fall of Biblical Archaeology. Oxford: OUP, 2004.

DEVER, William G. Retrospects and Prospects in Biblical Archaeology. BAR Vol. 45, 1982, p. 102-112.

DEVER, William G. Will the Real Israel Please Stand up: Archaeology and Israelite Historiography. BASOR. Vol. 297, 1995, p. 61-80.

DEVER, William G. Biblical Archaeology. In MEYERS, E.M. (ed.), The Oxford Encyclopedia of Archaeology in the Near East.Oxford: OUP, 1997, p. 315-319.

DEVER, William G. Excavating the Hebrew Bible, or Burying It Again? BASOR. Vol. 322, 2001, p. 67-77.

DEVER, William G. What Did the Biblical Writers Know and When Did They Know It?: Grand Rapids: Eerdmans, 2001.

DEVER, William G. Watchamacallit: Why It's so Hard to Name Our Field? BAR. Vol. 4, 2003, p. 56-61.

DEVER, William G. Who Were the Early Israelites, and Where Did They Come from? Grand Rapids: Eerdmans, 2003.

DEVER, William G., and CLARKE, M. The Patriarchal Traditions: Palestine in the Second Millennium BCE: the Archaeological Picture. In HAYES, J.H. and MILLER, J.M. (eds.) Israelite and Judaean History. London: S.C.M. Press, 1977, p. 70-120.

DÍAZ-ANDREU, Margarita. A World History pf Nineteenth-century arcaheology: Nationalism, colonialism and the past. Oxford: OUP, 2007. 
FAUST, Avraham. Did Eilat Mazar Find David's Palace? BAR. Vol. 38, Nr. 5, 2012, p. 47-52.

FINKELSTEIN, Israel. The Archaeology of the Israelite Settlement. Jerusalem: Israel Exploration Society, 1988.

FINKELSTEIN, Israel.. The Archaeology of the United Monarchy: An Alternative View. Levant. Vol. 28, Nr. 1, 1996, p. 177-87.

FINKELSTEIN, Israel. Digging for the Truth: Archaeology and the Bible. In SCHMIDT, B. (ed.) The Quest for the Historical Israel. Atlanta: Society of Biblical Literature, 2007, p. 9-20.

FINKELSTEIN, Israel. The "Large Stone Structure" in Jerusalem: Reality Versus Yearning.ZDPV. Vol. 127, Nr. 1, 2011, p. 1-10.

FINKELSTEIN, Israel. The Iron Age Chronology Debate: Is the Gap Narrowing? NEA. Vol. 74, Nr. 1, 2011, p. 50-54.

FINKELSTEIN, Israel; FANTALKIN, Alexander Khirbet Qeiyafa: An Unsensational Archaeolgical and Historical Interpretation. Tel Aviv. Vol. 39, 2012, p. 38-63.

FINKELSTEIN, Israel et al. Has the Palace of King David in Jerusalem Been Found? Tel Aviv. Vol. 34, 2007, p. 142-164.

FINKELSTEIN, Israel; PIASETZKY, E. Khirbet Qeiyafa: Absolute Chronology. Tel Aviv. Vol. 37, 2010, p. 84-88.

FINKELSTEIN, Israel; PIASETZKY, E. The Iron I/IIA transition in the Levant: A Reply to Mazar and Bronk Ramsey and a New Perspective. Radiocarbon. Vol. 52, Nr. 4, 2010, p. 1667-80.

FINKELSTEIN, Israel; SILBERMAN, Neil A. The Bible Unearthed: Archaeology's New Vision of Ancient Israel and the Origin of Its Sacred Texts. New York: Simon and Schuster, 2001.

FRANKEN, H.J.; FRANKEN-BATTERSHILL, C.A. A primer of Old Testament archaeology. Leiden: Brill, 1963.

FUNARI, Pedro Paulo A.; FERREIRA, Lucio M. A Social History of Brazilian Archaeology: a case study. BHA. Vol. 16, Nr. 2, 2008, p. 18-30.

GARFINKEL, Y.; GANOR, S. Khirbet Qeiyafa: The 2007-2008 Excavation seasons. Jerusalem: Israel Exploration Society, 2009. 
GARFINKEL, Y.; GANOR, S.; HASEL, M. G. Khirbet Qeiyafa: Excavation Report 2009-2013: Stratigraphy and Architecture (Areas B, C, D, E) Jerusalem: Israel Exploration Society, 2014.

GNECCO, Cristobal. Caminos de la Arqueología: de la violencia epistémica a la relacionalidad. Boletim do Museu Paraense Emilio Goeldi. Vol. 4, Nr. 1, 2009, p. 15-26.

GONZÁLEZ-RUIBAL. Introduction. In Reclaiming Archaeology. New York: Routledge, 2013, p. 1-30.

HABER, Alejandro F. Un-disciplining Archaeology. Archaeologies. Vol. 8, Nr. 1, 2012, p. 55-66.

HABER, Alejandro F.; ROBERTS, Amy. Histories of the Archaeological Discipline> Issues to consider. In SMITH (ed.) Encyclopedia of Global Archaeology.New York> Springer, 2014, p. 3411-3415.

HAMILAKIS, Yannis. The Nation and its ruins: Antiquity, archaeology, and national imagination in Greece. Oxford: OUP, 2009.

HINGLEY, Richard. Roman officers and English gentlemen: The Imperial origins of Roman archaeology. London: Routledge, 2000.

HODDER, Ian. Reading the Past. Cembridge: CUP, 2003.

HÜBNER, Ulrich. Biblische Archäologie Und Hebräische Lexikographie Im Hebräischen Handwörterbuch Von Gesenius. In $\mathrm{SCHORCH}$; WASCHKE (eds.) Biblische Exegese Und Hebräische Lexikographie. Berlin: de Gruyter, 2013.

KENYON, Kathleen. Archaeology in the Holy Land. New York: Praeger, 1960.

KOHL, Philip L.; FAWCETT, Clare P. Archaeology in the service of the State: theoretical considerations. Cambridge: CUP, 1995.

MAGNESS, Jodi. The Archaeology of the Holy Land: From the Destruction of Solomon's Temple to the Muslim Conquest. Cambridge: CUP, 2012.

MARCHAND, Suzanne, Down from Olympus: Archaeology and philhellenism in Germany, 1750-1970. Princeton: PUP, 1996.

MAZAR, Amihai. Archaeology of the Land of the Bible: 10,000-586 B.C.E. New York: Doubleday, 1990. 
MAZAR, Eilat. The Palace of King David Excavations at the Summit of the City of David: Preliminary Report of Seasons 2005-2007: Shoham Academic Research and Publication, 2009.

MAZAR, Eilat. Did I Find King David's Palace? BAR. Vol. 32, Nr. 1, 2006, p. 16-27.

NA'AMAN, Nadav. In Search of the Ancient Name of Khirbet Qeiyafa. Journal of Hebrew Scriptures. Vol. 8, 2008, 21.

NA'AMAN, Nadav. Shaaraim: The Gateway to the Kingdom of Judah. Journal of Hebrew Scriptures . Vol. 8, 2008, 24.

NEGEV, Avraham. Archaeological encyclopedia of the Holy Land. New York: Continuum, 2001.

ORSER, Charles E. Encyclopedia of Historical Archaeology. New York: Routledge, 2002.

RAD, Gerhard von. History and the Patriarchs. Expository Times. Vol. 72, Nr. 7, 1961, p. 213-216.

RAINEY, Anson F. Herodotus' Description of the East Mediterranean Coast. BASOR. Vol. 321, 2001, p. 57-63.

RAST, Walter E. Through the Ages in Palestinian Archaeology: An Introductory Handbook. Harrisburg: Trinity Press, 1992.

RENFREW, Colin; BAHN, Peter. Archaeology: Theories, Methods and Practice. London: Thames \& Hudson, 2008.

RODRIGUES, Gabriella. German Biblical Archaeology: Retrospective of a Neglected Legacy. Heidelberg: heiDOK, 2017 10.11588/heidok.00022796.

SHARON, Ilan. Biblical Archaeology. In PEARSALL, Deborah M. (ed.) Encyclopedia of Archaeology. New York: Academic Press, 2008; P: 920-24.

SILBERMAN, Neil A. Digging for God and Country: Exploration, Archeology, and the Secret Struggle for the Holy Land, 1799-1917. New York: Knopf, 1982.

SILBERMAN, Neil A. Between Past and Present: Archaeology, Ideology and Nationalism in the Middle East. New York: Henry Holt, 1989.

SILBERMAN, Neil A. Whose Game Is It Anyway? The Political and Social Transformations of American Biblical Archaeology. In MESKELL, 
Lynn (ed.) Archaeology Under Fire: Nationalism, Politics and Heritage in the Eastern Mediterranean and Middle East. London: Routledge, 1998, p. 175-188.

SOGGIN, Alberto J. Ancient Biblical Traditions and Modern Archaeological Discoveries. BA. Vol. 23, 1960, p. 95-100.

SUSSER, Asher. Israel, Jordan, and Palestine: The Two-State Imperative. Waltham: Brandeis University Press, 2012.

WRIGHT, George. E. Biblical Archaeology Today. BA. Vol. 10, Nr. 1, 1947, p. 7-24.

WRIGHT, George. E.. The Present State of Biblical Archaeology. In WILLOUGHBY, H.R. (ed.) The Study of the Bible Today and Tomorrow. Chicago: Univ. of Chicago Press, 1947.

WRIGHT, Ernest, G. Modern Issues in Biblical Studies: History and the Patriarchs. Expository Times. Vol. 71, Nr. 10, 1960, p. 292-296. 